\title{
PENINGKATAN KREATIVITAS DALAM MERINGKAS MELALUI LAYANAN PENGUASAAN KONTEN DENGAN METODE MIND MAPPING PADA SISWA KELAS VII.4 DI SMP NEGERI 04 KOTA BENGKULU
}

\author{
Riska Widya Andesma, Hadiwinarto \\ Prodi Bimbingan dan Konseling Fakultas Keguruan dan Ilmu Pendidikan \\ Universitas Bengkulu \\ riskawidyaandesma@gmail.com, kyhadiprabuono@yahoo.com
}

\begin{abstract}
ABSTRAK
Penelitian ini bertujuan untuk mendeskripsikan layanan penguasaan konten dengan metode mind mapping untuk meningkatkan kreativitas dalam meringkas pada siswa kelas VII.4 di SMP Negeri 04 Kota Bengkulu. Metode yang digunakan dalam penelitian ini adalah metode kuantitatif deskriptif dengan desain penelitian Time Series Design. Teknik pengumpulan data dilakukan melalui wawancara, lembar portofolio dan dokumentasi. Data dianalisis dengan rubrik kreativitas siswa dan uji $t$. Hasil penelitian menunjukkan bahwa adanya peningkatan yang signifikan terhadap kreativitas dalam meringkas siswa melalui layanan penguasaan konten dengan metode mind mapping, dengan nilai $t=-4.116$ dan sig. $0,003(\mathrm{p}$ $<0,05)$. Maka dapat disimpulkan ada peningkatan kreativitas dalam meringkas melalui layanan penguasaan konten dengan metode mind mapping pada siswa kelas VII.4 di SMP Negeri 04 Kota Bengkulu.
\end{abstract}

Kata kunci : kreativitas dalam meringkas, layanan penguasaan konten, mind mapping

\section{ENHANCEMENT OF CREATIVITY IN SUMMARIZING THROUGH THE CONTENT MASTERY SERVICES WITH MIND MAPPING METHOD STUDENTS IN GRADE VII.4 IN SMP NEGERI 04 BENGKULU CITY}

\begin{abstract}
This research aims to describe of content mastery services with the mind mapping method to increase creativity in summarizing the class VII.4 students in SMP Negeri 04 City of Bengkulu. The methods used in this study are quantitative descriptive with design of research Time Series Design. Data collection techniques are conducted through interviews, portfolio sheets and documentation. Analytical data with the students creativity rubric and testing a t. The research shows that there is a significant increase to creativity in summarizing through content mastery services with the mind mapping method, with value $t=-4.166$ and sig. 0,003 $(\mathrm{p}<0,05)$. Then it can be concluded there is an increase creativity in summarizing trough the content mastery services with the mind mapping method the class VII.4 students in SMP Negeri 04 City of Bengkulu.
\end{abstract}

Keywords : creativity in summarizing, content mastery services, mind mapping 


\section{Pendahuluan}

Proses belajar mengajar dalam dunia pendidikan merupakan bagian yang terpenting bagi perkembangan peserta didik. Belajar merupakan tugas utama yang harus dilakukan oleh siswa. Siswa melakukan proses belajar agar mendapatkan ilmu yang bisa dijadikan modal dalam menjalani kehidupan sehari-hari. Belajar akan berhasil apabila tujuan yang ditetapkan bisa tercapai dan siswa mampu menerapkan apa yang telah dipelajari dalam kehidupan sehari-hari. Diperlukan usaha-usaha yang tepat untuk mencapai keberhasilan belajar yang diinginkan. Usaha-usaha tersebut dapat dilakukan oleh siswa atau guru. Salah satu usaha yang harus dilakukan siswa adalah menggunakan cara belajar yang tepat agar dalam proses pembelajaran merasa nyaman. Sedangkan yang harus dilakukan guru adalah menentukan metode pengajaran yang tepat, agar siswa tidak merasa bosan saat menerima materi yang diberikan (Latih, $2014: 1$ ).

Pelaksanaan kegiatan proses belajar mengajar tidak lepas dari berbagai masalah belajar, masalah belajar merupakan inti dari kegiatan di sekolah yang diperuntukkan bagi berhasilnya proses belajar untuk setiap siswa yang sedang belajar Ahmad \& Supriyono (dalam Noviani, 2015: 1). Salah satu masalah belajar yaitu berkaitan dengan masalah keterampilan belajar. Agar siswa merasa nyaman dalam proses pembelajaran diperlukan keterampilanketerampilan dalam belajar dan keterampilan guru dalam mengajar.

Keterampilan belajar perlu dikuasai siswa karena belajar merupakan kegiatan yang mempunyai tujuan. Tujuan belajar menurut Wahono (dalam Umami, 2015: 41) adalah untuk memperoleh pengetahuan, kecakapan, pengalaman, dan sikap yang diperlukan untuk kesuksesan hidup. Menurut Gie (dalam Umami, 2015: 41) keterampilan belajar dapat diartikan sebagai seperangkat sistem, metode, dan teknik yang baik dalam usaha menguasai materi pengetahuan yang disampaikan guru secara tangkas, efektif dan efisien, sementara itu menurut Prayitno (dalam Umami, 2015: 41) kegiatan belajar seharusnya dilaksanakan dengan menerapkan berbagai keterampilan yang meliputi keterampilan dasar membaca, menulis, menghitung, keterampilan mengikuti pelajaran di dalam kelas, membuat catatan, bertanya, dan menjawab (baik lisan, maupun tulisan), mengerjakan tugas, membuat laporan, menyusun makalah, menyiapkan dan mengikuti ujian, serta menindak lanjuti hasil mengerjakan tugas, ulangan, atau ujian.

Fenomena-fenomena yang terjadi di lapangan khususnya di SMP N 04 Kota Bengkulu, metode belajar dan mengajar yang diterapkan oleh siswa dan guru masih sering 
menggunakan metode konvensional. Pada pembelajaran konvensional semua proses pembelajaran terpusat pada guru, siswa hanya duduk dan mendengarkan informasi yang disampaikan oleh guru dan mencatat dalam bentuk catatan yang monoton.

Penggunaaan metode belajar yang tepat akan menumbuhkan minat belajar pada diri siswa dan mampu memperoleh keberhasilan belajar siswa. Dengan metode belajar yang menarik siswa diharapkan lebih termotivasi dan menambah rasa puas terhadap hasil belajarnya. Salah satu alternatif metode belajar yang dapat meningkatkan keterampilan belajar serta kreativitas dalam meringkas siswa adalah dengan menggunakan metode mind mapping.

Buzan (dalam Fadhilaturrahmi, 2017: 113) menyampaikan bahwa "mind mapping merupakan cara termudah untuk menempatkan informasi ke dalam otak dan mengambil informasi ke luar dari otak. Mind mapping adalah cara mencatat kreatif, efektif dan secara harfiah akan memetakan pikiran-pikiran kita, dengan mind mapping daftar informasi yang panjang bisa dialihkan menjadi diagram warna-warni, sangat teratur dan mudah diingat yang bekerja selaras dengan cara kerja otak dalam melakukan berbagai hal. Cara ini adalah cara kreatif dan efektif dalam membuat catatan". Selanjutnya De Porter \& Hernacki (dalam Noviasari, 2014: 4) menjelaskan, mind mapping merupakan teknik pemanfaatan keseluruhan otak dengan menggunakan citra visual dan prasarana grafis lainnya untuk membentuk suatu kesan yang lebih dalam.

Pembelajaran menggunakan mind mapping merupakan salah satu metode yang dapat dijadikan alternatif guru untuk mengajar. Salah satu layanan bimbingan dan konseling dalam membantu siswa untuk menerapkan metode mind mapping adalah layanan penguasaan konten. Layanan penguasaan konten merupakan layanan bantuan kepada individu (sendirisendiri ataupun dalam kelompok) untuk menguasai kemampuan atau kompetensi sesuatu tertentu melalui kegiatan belajar (Prayitno, 2004: 2). Layanan penguasaan konten lebih diarahkan membantu siswa menguasai suatu keterampilan maupun kebiasaan yang bermanfaat dalam kehidupan sehari- harinya. Titik point dari layanan ini adalah adanya perubahan sikap, perilaku, atau kebiasaan pada individu setelah diberikan konten tertentu.

Berdasarkan dari uraian di atas peneliti tertarik untuk melakukan penelitian tentang belajar dengan metode mind mapping dengan judul "Peningkatan Kreativitas Dalam Meringkas Melalui Layanan Penguasaan Konten Dengan Metode Mind Mapping Pada Siswa Kelas VII.4 di SMP Negeri 04 Kota Bengkulu”. 


\section{Metode Penelitian}

Penelitian ini menggunakan metode kuantitatif deskriptif dengan desain penelitian Time Series Design. Analisis data melalui metode deskriptif adalah analisis yang didasarkan pada kondisi ilmiah sebagai keutuhan penelitian. Menurut Sugiyono metode penelitian kuantitatif adalah metode penelitian yang berdasarkan pada filsafat positivism, yang digunakan untuk meneliti pada populasi atau sampel tertentu. Pengambilan subjek penelitian dilakukan secara random, yaitu dengan mengambil salah satu kelas diantara kelas yang ada pada populasi yaitu siswa kelas VII.4 SMP Negeri 04 Kota Bengkulu yang berjumlah 33 siswa.

Teknik pengumpulan data merupakan langkah yang paling strategis dalam penelitian, karena tujuan utama dari penelitian adalah mendapatkan data. Tanpa mengetahui teknik pengumpulan data, maka peneliti tidak akan mendapatkan data yang memenuhi standar data yang ditetapkan (Sugiyono, 2015: 62). Teknik Pengumpulan data dalam penelitian ini adalah menggunakan observasi, lembar portofolio dalam bentuk mind mapping, dan dokumentasi. Analisis data yang digunakan dalam penelitian ini adalah deskriptif analisis, dimana analisisnya mengarah pada induktif yaitu suatu yang khusus dari kejadian-kejadian yang ditemukan di lapangan untuk sesuatu yang bersifat umum yang lebih luas. Metode deskripsi digunakan untuk memperoleh gambaran tentang suatu keadaan yang langsung pada saat sekarang. Metode ini ditempuh melalui langkah-langkah sebagai berikut : pengumpulan data, analisis data atau pengelolaan data serta membuat kesimpulan dengan tujuan utamanya membuat gambaran tentang suatu keadaan secara nyata dan objektif.

Langkah awal yaitu mengumpulkan data berupa lembar portofolio siswa dalam bentuk mind mapping, kemudian lembar portofolio tersebut diberikan penilaian sesui dengan apa yang siswa kerjakan. Penentuan kategori penilaian terhadap lembar portofolio siswa pada kegiatan dengan membuat mind mapping dilakukan dengan menghitung skor dari tiap indikator lembar format penilaian mind mapping. Format penilaian mind mapping diambil dari yang dikembangkan oleh mind mapping rubric from Ohassta dan rubrik dari Ertug Evrekli, dkk (dalam Sari dan Susilo, 2016 : 667-668). Format Penilaian tersebut dapat dilihat pada Tabel 1. 
Tabel 1

Format Penilaian Kreativitas Mind Mapping

\begin{tabular}{|c|c|c|c|c|c|}
\hline \multirow{2}{*}{ Kriteria } & \multicolumn{5}{|c|}{ Skor } \\
\hline & 5 & 4 & 3 & 2 & 1 \\
\hline $\begin{array}{c}\text { Kata } \\
\text { Kunci }\end{array}$ & $\begin{array}{c}\text { Ide dalam } \\
\text { bentuk kata } \\
\text { kunci yang } \\
\text { sangat efektif }\end{array}$ & $\begin{array}{l}\text { Ide dalam } \\
\text { bentuk kata } \\
\text { kunci dan } \\
\text { kalimat } \\
\text { efektif }\end{array}$ & $\begin{array}{l}\text { Ide dalam } \\
\text { bentuk kata } \\
\text { kunci dan } \\
\text { kalimat } \\
\text { cukup efektif }\end{array}$ & $\begin{array}{l}\text { Penggunaan } \\
\text { kata kunci } \\
\text { terbatas } \\
\text { (semua ide } \\
\text { ditulis dalam } \\
\text { bentuk } \\
\text { kalimat) }\end{array}$ & $\begin{array}{c}\text { Tidak ada } \\
\text { atau sangat } \\
\text { terbatas } \\
\text { dalam } \\
\text { pemilihan } \\
\text { kata kunci } \\
\text { (beberapa } \\
\text { ide ditulis } \\
\text { dalambentu } \\
\text { k paragraf) }\end{array}$ \\
\hline $\begin{array}{c}\text { Hubunga } \\
\text { n Cabang } \\
\text { Utama } \\
\text { Dengan } \\
\text { Cabang } \\
\text { Lainnya }\end{array}$ & $\begin{array}{l}\text { Menggunakan } \\
\text { Lebih dari } 4 \\
\text { cabang }\end{array}$ & $\begin{array}{c}\text { Menggunaka } \\
\text { n } \\
4 \text { cabang }\end{array}$ & $\begin{array}{c}\text { Menggunaka } \\
\text { n } \\
3 \text { cabang }\end{array}$ & $\begin{array}{c}\text { Menggunaka } \\
n \\
2 \text { cabang }\end{array}$ & $\begin{array}{c}\text { Hanya } \\
\text { menggunak } \\
\text { an } \\
1 \text { cabang }\end{array}$ \\
\hline $\begin{array}{l}\text { Desain } \\
\text { Warna }\end{array}$ & $\begin{array}{c}\text { Menggunakan } \\
\text { warna untuk } \\
\text { menunjukkan } \\
\text { hubungan } \\
\text { semua topik } \\
\text { sangat baik }\end{array}$ & $\begin{array}{l}\text { Menggunaka } \\
\text { n warna } \\
\text { untuk } \\
\text { menunjukkan } \\
\text { beberapa } \\
\text { hubungan } \\
\text { antar topik } \\
\text { baik }\end{array}$ & $\begin{array}{c}\text { Menggunaka } \\
\mathrm{n} \\
\text { beberapa } \\
\text { warna tapi } \\
\text { tidak } \\
\text { menunjukkan } \\
\text { hubungan } \\
\text { yang cukup } \\
\text { baik } \\
\end{array}$ & $\begin{array}{l}\text { Menggunaka } \\
\text { n sedikit } \\
\text { warna dan } \\
\text { tidak } \\
\text { menunjukkan } \\
\text { hubungan } \\
\text { antar topik } \\
\text { kurang baik }\end{array}$ & $\begin{array}{c}\text { Hanya } \\
\text { menggunak } \\
\text { an satu } \\
\text { warna } \\
\text { untuk } \\
\text { menunjukk } \\
\text { an } \\
\text { hubungan } \\
\text { antar topik } \\
\end{array}$ \\
\hline $\begin{array}{l}\text { Simbol } \\
\text { Gambar } \\
\text { dan } \\
\text { Garis } \\
\text { Lengkun } \\
\text { g }\end{array}$ & $\begin{array}{c}\text { Menggunakan } \\
\text { gambar/simbol } \\
\text { pada ide } \\
\text { sentral, cabang } \\
\text { utama dan } \\
\text { cabang } \\
\text { lainnya yang } \\
\text { dihubungkan } \\
\text { dengan garis } \\
\text { lengkung } \\
\end{array}$ & $\begin{array}{c}\text { Menggunaka } \\
\mathrm{n} \\
\text { gambar/simb } \\
\text { ol pada ide } \\
\text { sentral dan } \\
\text { cabang utama } \\
\text { yang } \\
\text { dihubungkan } \\
\text { dengan garis } \\
\text { lengkung } \\
\end{array}$ & $\begin{array}{c}\text { Menggunaka } \\
\mathrm{n} \\
\text { gambar/simb } \\
\text { ol hanya pada } \\
\text { ide sentral } \\
\text { atau cabang } \\
\text { utama yang } \\
\text { dihubungkan } \\
\text { dengan garis } \\
\text { lengkung }\end{array}$ & $\begin{array}{c}\text { Tidak } \\
\text { menggunakan } \\
\text { gambar/simb } \\
\text { ol tapi } \\
\text { menggunakan } \\
\text { garis } \\
\text { lengkung }\end{array}$ & $\begin{array}{l}\text { Menggunak } \\
\text { an garis } \\
\text { lurus } \\
\text { sebagai } \\
\text { penghubun } \\
\text { g cabang }\end{array}$ \\
\hline $\begin{array}{l}\text { Kelengk } \\
\text { apan } \\
\text { Materi }\end{array}$ & $\begin{array}{l}\text { Peta pikiran } \\
\text { menunjukkan } \\
\text { materi yang } \\
\text { sangat } \\
\text { kompleks }\end{array}$ & $\begin{array}{l}\text { Peta pikiran } \\
\text { menunjukkan } \\
\text { materi yang } \\
\text { kompleks }\end{array}$ & $\begin{array}{l}\text { Peta pikiran } \\
\text { menunjukkan } \\
\text { materi yang } \\
\text { cukup } \\
\text { kompleks }\end{array}$ & $\begin{array}{l}\text { Peta pikiran } \\
\text { menunjukkan } \\
\text { materi yang } \\
\text { kurang } \\
\text { kompleks }\end{array}$ & $\begin{array}{c}\text { Peta } \\
\text { pikiran } \\
\text { menunjukk } \\
\text { an materi } \\
\text { yang tidak } \\
\text { kompleks }\end{array}$ \\
\hline
\end{tabular}

Sumber: Adaptasi Mind Mapping Rubric From Ohassta (Ontario history and social science teachers'association dan Ertug Evrekli, Didem Inel, dan Ali Gunay Balim (dalam Sari dan Susilo, 2016 : 667-668). 
Berdasarkan format penilaian mind mapping diatas kategori kreativitas siswa dikelompokkan menjadi lima tingkatan seperti pada Tabel 2.

Tabel 2

Kategori Penilaian Mind Mapping Siswa

\begin{tabular}{cc}
\hline Skor & Kriteria \\
\hline $1-5$ & Sangat Rendah \\
\hline $6-10$ & Rendah \\
\hline $11-15$ & Sedang \\
\hline $16-20$ & Tinggi \\
\hline $21-25$ & Sangat Tinggi \\
\hline
\end{tabular}

Berdasarkan kategori penilaian yang telah ditentukan diatas, maka semakin tinggi skor total yang diperoleh maka semakin tinggi kreativitas dalam meringkas siswa. Demikian pula sebaliknya, semakin rendah skor total diperoleh maka semakin rendah kreativitas dalam meringkas siswa.

Dalam Penelitian kali ini juga digunakan teknik analisis data menggunakan komputer dengan aplikasi SPSS 16 For Windows untuk melihat kenaikan signifikan dari kreativitas dalam meringkas siswa. Pengujian hipotesis menggunakan rumus uji $t$ (t-test) untuk melihat apakah ada peningkatan kreativitas dalam pembuatan mind mapping. Uji $t$ yang digunakan dalam penelitian kali ini menggunakan analisis Paired Sample T-Test dengan pengambilan keputusan yakni, jika probabilitas > 0,05, maka $\mathrm{H}_{0}$ diterima. Tapi jika jika probabilitas < 0,05, maka $\mathrm{H}_{0}$ ditolak dan Ha diterima.

\section{Hasil dan Pembahasan}

Deskripsi data yang disajikan dalam penelitian ini adalah dengan deskripsi data hasil peningkatan kreativitas dalam meringkas siswa dari awal pertemuan hingga pertemuan terkahir. Buzan (dalam Sholihah, 2015: 3) kreativitas adalah kemampuan berpikir dengan cara baru menjadi orisinil. Mengembangkan ide pemikir yang kreatif mampu membangun diri, mengembangkan, menghias, melebih-lebihkan dan mengembangkan ide-ide. Pemikiran kreatif melibatkan penggunaan seluruh keterampilan mental otak kiri dan otak kanan. Anak yang memiliki kreativitas biasanya selalu ingin tau, memiliki minat yang luas, menyukai kegemaran dan aktivitas yang kreatif, biasanya cukup mandiri dan memiliki rasa percaya diri, serta lebih berani mengambil resiko dan berani mengemukakan pendapat mereka Munandar (2009: 35). 
Deskripsi tentang peningkatan kreativitas dalam meringkas siswa diperoleh dari penilaian lembar portofilio dalam bentuk mind mapping yang dikerjakan siswa selama lima kali pertemuan. Penentuan kategori penilaian terhadap lembar portofolio siswa pada kegiatan membuat mind mapping dilakukan dengan menghitung skor dari tiap indikator lembar format penilaian mind mapping.

Berikut hasil penilaian keseluruhan terhadap lembar portofolio siswa dari setiap pertemuan, hasil tersebut dapat dilihat pada Tabel 3 dibawah ini :

Tabel 3

Hasil Penilaian Kreativitas Mind Mapping Siswa

\begin{tabular}{|c|c|c|c|c|c|c|}
\hline \multirow{2}{*}{ No } & \multirow{2}{*}{ Responden } & \multicolumn{5}{|c|}{ Skor Per Pertemuan } \\
\hline & & 1 & 2 & 3 & 4 & 5 \\
\hline 1 & AHS & 12 & 12 & 14 & 14 & 17 \\
\hline 2 & ARE & 10 & 16 & 15 & 14 & 17 \\
\hline 3 & AT & 10 & 14 & 18 & 18 & 14 \\
\hline 4 & DRS & 16 & 13 & 13 & 14 & 17 \\
\hline 5 & EMD & 11 & 9 & 14 & 12 & 16 \\
\hline 6 & $\mathrm{SAH}$ & 10 & 11 & 14 & 18 & 21 \\
\hline 7 & TN & 12 & 15 & 11 & 18 & 13 \\
\hline 8 & VTL & 9 & 13 & 18 & 13 & 11 \\
\hline 9 & VNY & 16 & 18 & 18 & 13 & 17 \\
\hline 10 & WCP & 10 & 10 & 13 & 19 & 19 \\
\hline & Jumlah & 116 & 131 & 148 & 153 & 162 \\
\hline & Rata-rata & 11,6 & 13,1 & 14,8 & 15,3 & 16,2 \\
\hline
\end{tabular}

Berdasarkan tabel 3 diatas dapat dilihat bahwa skor rata-rata pada lima kali pertemuan mengalami peningkatan paling tinggi terjadi pada pertemuan ke-5 dengan rata-rata 16,2 , selanjutnya pada pertemuan ke-4 dengan rata-rata 15,3, lalu pada pertemuan ke-3 dengan rata-rata 14,8, selanjutnya pada pertemuan ke-2 dengan rata-rata 13,1 , dan terakhir pada pertemuan pertama dengan rata-rata 11,6. Berdasarkan data yang dimiliki untuk uji $t$ didapati hasil sebagai berikut :

Tabel 4

Hasil Uji Sampel T Test

\begin{tabular}{ccc}
\hline Series & $T$ & Sig. \\
\hline $1-5$ & -4.116 & .003 \\
\hline
\end{tabular}

Berdasarkan Tabel 4 dapat dilihat pada nilai $t=-4,116$ dengan Sig. (2-tailed) adalah 0,003 yang artinya nilai sig (2-tailed) $0,003<0,05$. Berdasarkan kriteria penerimaan atau 
penolakan hipotesis itu berarti $\mathrm{H}_{0}$ ditolak dan $\mathrm{H}_{\mathrm{a}}$ diterima, dengan demikian dapat disimpulkan bahwa terdapat peningkatan kreativitas dalam meringkas melalui layanan penguasaan konten dengan metode mind mapping pada siswa kelas VII.4 di SMP Negeri 04 Kota Bengkulu. Layanan penguasaan konten dinilai efektif dalam meningkatkan kreativitas meringkas siswa karena layanan penguasaan konten memiliki fungsi utama sebagai pemeliharaan dan pengembangan. Dalam pengembangan sikap belajar seperti mengatur jadwal belajar, cara yang digunakan dalam belajar, memotivasi dan berkonsentrasi saat belajar. Pemberian layanan penguasaan konten juga dapat memberikan pengaruh positif terhadap kreativitas dalam meringkas siswa. Dengan memberikan pemahaman dan latihan kepada siswa dapat memberikan perubahan secara langsung agar siswa dapat menguasai kemampuan atau kompetensi dalam belajar untuk menambah wawasan dan pemahamannya di bidang belajar.

Penelitian ini telah diusahakan dan dilaksanakan sesuai dengan prosedur ilmiah, namun masih memiliki keterbatasan, yaitu : penelitian ini hanya terbatas pada materi PPKN saja dan tidak membahas materi yang lainnya, penelitian ini hanya berlaku pada siswa kelas VII.4 saja sebagai sampel dari penelitian, keterbatasan dalam penelitian mengenai durasi waktu pemberian layanan kepada siswa yang hanya 40 menit dalam setiap kali pemberian layanan, dan keterbatasan lain dalam penelitian ini kondisi ruang bimbingan dan konseling yang kurang kondusif dengan fasilitas seadanya.

\section{Kesimpulan}

Berdasarkan hasil penelitian yang telah dilaksanakan pada siswa kelas VII.4 SMP Negeri 04 Kota Bengkulu, kreativitas dalam meringkas siswa pada pertemuan pertama diberikan layanan penguasaan konten memiliki nilai rata-rata sebesar 11,6. Hal ini menunjukkan bahwa kreativitas dalam meringkas siswa masih tergolong sedang, sedangkan pada pertemuan terakhir kreativitas dalam meringkas siswa kelas VII.4 SMP Negeri 04 Kota Bengkulu meningkat menjadi 16,2. Jadi, dapat disimpulkan bahwa terdapat peningkatan kreativitas dalam meringkas siswa kelas VII.4 SMP Negeri 04 Kota Bengkulu melalui layanan penguasaan konten dengan metode mind mapping.

\section{Daftar Pustaka}

Fadhilaturrahmi. (2017). Penerapan Metode Mind Mapping Untuk Meningkatkan Hasil Belajar Mahasiswa Semester IIA PGSD Mata Kuliah Pendidikan Matematika SD Kelas Rendah. Jurnal Pendidikan Matematika. 1(2), 112-121. 
Latih, Y. E. P. (2014). Efektivitas Bimbingan Belajat Teknik Peta Pikiran (Mind Map) Untuk Meningkatkan Keterampilan Belajar Siswa. Jurnal Bimbingan dan Konseling. 1 (2), $1-13$.

Munandar, U. (2009). Pengembangan Kreativitas Anak Berbakat. Jakarta: Rineka Cipta.

Noviani, D. (2015). Peran Layanan Bimbingan Belajar Dengan Peta Pikiran (Mind Map) Terhadap Kemampuan Mengingat Siswa Kelas VII Di SMP Negeri 11 Kota Bengkulu. Skripsi. FKIP UNIB.

Noviasari. (2014). Metode Belajar Menggunakan Mind Map Untuk Meningkatkan Kreativitas Pada Peserta Didik Kelas VIII SMP Negeri 2 Kartasura Tahun Ajaran 2013/2014. Jurnal Bimbingan dan Konseling.

Prayitno. (2004). Kegiatan Pendukung Konseling (L1-L9). Padang: FIP UNP.

Umami, I. (2015). Keterampilan Belajar Sebagai Komponen Layanan Penguasaan Konten Dalam Bimbingan Konseling. Jurnal Ilmu Bimbingan dan Konseling, 5(1), 40-49.

Sari, F. N dan Susilo. H. (2016). Penggunaan Peta Pikiran (Mind Mapping) Sebagai Instrumen Penilaian Kreativitas Mahasiswa Calon Guru Biologi Pada Mata Kuliah Metodologi Penelitian Berbasis Lesson Study. Jurnal Pendidikan Biologi.

Sholihah, M. (2015). Penerapan Model Pembelajaran Mind Mapping Untuk Meningkatkan Kreativitas dan Hasil Belajar Siswa Pada Mata Pelajaran Ekonomi Kelas X IPS Di SMA Negeri 8 Malang Semester Genap Tahun Ajaran 2013/2014. Jurnal Bimbingan dan Konseling.

Sugiyono. (2015). Memahami Penelitian Kuantitatif. Bandung: Alfabeta. 